\title{
EMPREGO DE CROMATOGRAFIA LÍgUIDA DE ALTA EFICIÊNCIA HIDROFÍLICA NA DETERMINAÇÃO DOS AMINOÁCIDOS DE HIDROLISADOS DE CASEÍNA ${ }^{1}$
}

\author{
Raquel Linhares CARREIRA², Cristiane Márcia da Silva BARBOSA³, Roberto Gonçalves JUNQUEIRA³, \\ Silvana da MOTTA ${ }^{3}$, Marialice Pinto Coelho SILVESTRE ${ }^{3, *}$

\section{RESUMO} \\ O emprego de cromatografia líquida de alta eficiência de interação hidrofílica (HILIC) foi estudado visando a separação e a quantificação \\ dos aminoácidos essenciais. Alguns parâmetros foram testados, tais como a composição da fase móvel e a velocidade do fluxo. Deter- \\ minou-se, ainda, o limite de quantificação, a linearidade e a repetibilidade desta técnica. Os resultados obtidos indicaram as vantagens \\ desta metodologia em termos de tempo, economia e simplicidade, quando comparada a outras técnicas de determinação dos aminoá- \\ cidos, uma vez que dispensa a derivação pré-coluna e permite trabalhar em modo isocrático. A sua aplicação, na análise de frações \\ cromatográficas de hidrolisados de caseina, revelou a importância da HILIC na avaliação nutricional destas preparações. \\ Palavras-chave: hidrolisados de caseína; aminoácidos essenciais; cromatografia líquida de alta eficiência de interação hidrofilica.
}

\section{SUMMARY}

USE OF HIGH PERFORMANCE LIQUID HYDROPHILIC CHROMATOGRAPHY FOR DETERMINING AMINO ACIDS IN CASEIN HYDROLYSATES. In this work, the use of hydrophilic-interaction chromatography (HILIC) was thoroughly studied for the first time in order to separate and quantify essential amino acids. Some parameters, such as the composition of the mobile phase and the flow rates were studied. The detection limit, the linearity and the repetibility of this technique were also determined. The results showed that, comparing to other methods for analysing amino acids mixtures, this technique presented some advantages, in terms of time, economy and simplicity, since the pre-column derivatisation is not needed and an isocratic condition can also be used. The utilisation of this technique for analysing the chromatography fractions of casein hydrolysates showed the importance of HILIC in the nutritional evaluation of these preparations.

Keywords: casein hydrolysates; essential amino acids; high performance liquid hydrophilic chromatography.

\section{1 - INTRODUÇÃO}

A determinação dos aminoácidos vem sendo usada, há muito tempo, na pesquisa bioquímica e, mais recentemente, na área de ciência de alimentos, no intuito de melhor se conhecer a composição das proteinas. Sabendo-se que os aminoácidos são unidades estruturais básicas das proteinas, a quantificação e a qualificação dos mesmos tornam-se necessárias [12], uma vez que, o principal fator determinante da qualidade da proteína é a sua composição em aminoácidos [4, 22]. Portanto, a determinação desta composição é um dos primeiros passos na compreensão da estrutura da molécula da proteína, sendo de grande importância, a análise precisa e quantitativa destes aminoácidos, a fim de se verificar o valor nutricional das proteínas [22].

A técnica de determinação dos aminoácidos foi iniciada por MOORE et al. [14], empregando uma resina sulfonatada de troca iônica, sendo que, a detecção dos aminoácidos era realizada por colorimetria, após a reação pós-coluna, com ninidrina. Posteriormente, introduziu-se a cromatografia líquida de alta eficiência (HPLC), utilizando um equipamento mais econômico e versátil que um analisador de aminoácidos de troca iônica [11]. Assim, várias técnicas de cromatografia liquida de fase reversa (HPLC-RP), empregando gradiente de eluição,

1. Recebido para publicação em 08/08/2000. Aceito para publicação em $14 / 03 / 2002$.

2. Autora da dissertação de mestrado da qual este artigo faz parte

3. Departamento de Alimentos, Faculdade de Farmácia da UFMG, Av. Olegário Maciel, 2360, CEP: 30180-112, Belo Horizonte, MG. E-mail: malice@farmacia.ufmg.br.

* A quem a correspondência deve ser enviada. diferentes tipos de coluna e detectores, seguida da derivação das amostras com reagentes variados, estão sendo utilizadas para a determinação dos aminoácidos [1, $5,7,21]$.

A HPLC com interação hidrofilica (HILIC) foi introduzida na década de 1990 para a separação e purificação de peptídeos, ácidos nucléicos e outros compostos polares [2, 24]. Nesta técnica, os solutos são eluídos de acordo com o aumento de sua hidrofilicidade e, ainda, podem ser associados à fase móvel reagentes como o ácido ortofosfórico, capazes de aumentar a hidrofilicidade dos peptídeos [23]. Dentre estes estudos, apenas ALPERT et al. [2] mostrou o resultado da separação de 13 aminoácidos, empregando-se dois tipos de coluna, a PHEA [poli-(2-hidroxietilaspartamida)-sílica] e a PSA (polisulfoetil aspartamida).

O valor nutricional das proteinas alimentares está relacionado ao seu conteúdo em aminoácidos essenciais, associado a sua digestibilidade, justificando-se assim, a importância de se analisar estes compostos presentes nos hidrolisados de caseína. Além disso, a presença destes aminoácidos nos hidrolisados protéicos, sob a forma de di- tripeptídeos, propicia uma melhor utilização das proteinas, visto que, os oligopeptídeos, são mais fáceis e rapidamente absorvidos pelo organismo [22].

Neste trabalho, procurou-se, inicialmente, explorar o potencial da HILIC na determinação dos aminoácidos essenciais, empregando-se a coluna PHEA. Em seguida, esta técnica foi utilizada na análise de frações cromatográficas de hidrolisados de caseína. A vantagem desta técnica, sobre as citadas anteriormente, relaciona-se à possibilidade de redução de tempo e custo, uma vez que 
não necessita da derivação pré-coluna e, ainda, pode-se trabalhar em modo isocrático.

\section{2 - MATERIAL E MÉTODOS}

\section{1 - Equipamentos}

O sistema de HPLC consistiu de uma bomba isocrática (série HP1100), um detector espectrofotométrico UV-VIS ( $\lambda$ variável, série HP1100, Waldbronn, Alemanha), acoplado a um computador com software HP Chemstation, todos da Hewlett-Packard (Avondale, PA, EUA). As análises cromatográficas foram realizadas utilizando-se a coluna PHEA [poli-(2-hidroxietilaspartamida)-sílica], 250x9,4mm, tamanho da partícula de $5 \mu \mathrm{m}$ e do poro $300 \AA$ (PolyLc, Columbia, MD, EUA).

\section{2 - Reagentes}

O kit de L-aminoácidos L-AA 21 foi adquirido da Sigma (St. Louis, MO, EUA). O ácido clorídrico e a acetonitrila, grau HPLC, foram adquiridos da Merck (Darmstad, Alemanha). A água para uso no cromatógrafo foi purificada através do sistema de purificação de água Aries (Vaponics, Rockland, Massachusetts, EUA), e as soluções foram filtradas, empregando-se uma membrana de $0,45 \mu \mathrm{m}$ em um sistema de filtração (Millipore, Bedford, EUA). Todos os solventes usados no cromatógrafo foram desgaseificados no banho de ultra-som, antes do uso.

\section{3 - Preparo do padrão de aminoácidos}

A solução padrão contendo os oito aminoácidos essenciais foi preparada pesando-se quantidades variáveis de cada aminoácido, de maneira a obter uma concentração final entre $1 \mathrm{mmol} / \mathrm{mL}$ e $55 \mu \mathrm{mol} / \mathrm{mL}$ de fase móvel.

\section{4 - Condições Cromatográficas}

Utilizou-se um sistema de HPLC, em modo isocrático, para a determinação dos aminoácidos essenciais. A fase móvel empregada consistiu de acetonitrila/trietilaminafosfato (TEAP, 10mmol/L), pH 2,8 (70:30, v/v). A injeção da amostra $(20 \mu \mathrm{L})$ foi efetuada manualmente, e a detecção ocorreu a $215 \mathrm{~nm}$. A separação cromatográfica foi realizada a um fluxo constante de $1 \mathrm{~mL} / \mathrm{min}$, à temperatura de $25^{\circ} \mathrm{C}$.

\section{5 - Curva de calibração}

A curva de calibração foi construída com seis pontos, traçando-se um gráfico das áreas dos picos obtidos pela injeção de $20 \mu \mathrm{L}$ da solução de aminoácido preparada numa faixa de $0,02 \mathrm{nmol}$ a $1100 \mathrm{nmol}$ para lisina, de $0,02 \mathrm{nmol}$ a $0,1 \mathrm{nmol}$ para triptofano, de 0,02nmol a 0,06nmol para fenilalanina, de 50nmol a $600 \mathrm{nmol}$ para leucina, de $50 \mathrm{nmol}$ a $500 \mathrm{nmol}$ para isoleucina e metionina, de 200nmol a 700nmol para valina e de $50 \mathrm{nmol}$ a $600 \mathrm{nmol}$ para treonina. A repetibilidade do método foi verificada através da injeção, em triplicata. Em cada curva de calibração, o primeiro ponto corresponde ao limite de quantificação nas condições empregadas, ou seja, a menor quantidade detectável pelo método.

\section{6 - Preparo das amostras}

Com o objetivo de se estudar a composição em aminoácidos essenciais de hidrolisados protéicos, selecionou-se os três hidrolisados de caseina que apresentaram o melhor perfil peptídico para suplementos dietéticos, em trabalho anteriormente realizado (dados do autor, ainda não publicados) [6], e aqui foram denominados de $\mathrm{H} 1, \mathrm{H} 2$ e H3.

Os hidrolisados foram fracionados por HPLC-SE em coluna PHEA, como descrito por SILVESTRE, HAMON, YVON [19], e as quatro frações cromatográficas $F 1$ (13,5 a $18 \mathrm{~min}), \mathrm{F} 2$ (18 a $21,5 \mathrm{~min}), \mathrm{F} 3$ (21,5 a $22,5 \mathrm{~min})$ e F4 $(22,5$ a $32 \mathrm{~min})$, foram coletadas utilizando-se o coletor automático (Spectra/Chrom, Houston, EUA).

\section{7 - Hidrólise ácida das frações cromatográficas}

As aliquotas retiradas das quatro frações cromatográficas, obtidas através da HPLC-SE, foram evaporadas a $35^{\circ} \mathrm{C}$ no concentrador de amostras Centrivap (Labconco, Kansas City, EUA), e as frações F1, F2 e F3 foram hidrolisadas ( $\left.\mathrm{HCl} 5,7 \mathrm{~mol} / \mathrm{L}, 110^{\circ} \mathrm{C}, 24 \mathrm{~h}\right)$. Após este tratamento, as amostras foram dissolvidas em $1000 \mu \mathrm{L}$ de fase móvel, filtradas em membranas de $0,22 \mu \mathrm{m}$ e injetadas no sistema cromatográfico, segundo ALAIZ et al. [1], BADOUD \& PRATZ [3] e SIVESTRE, HAMON, YVON [19].

\section{8 - Análise estatística}

Todas as análises foram realizadas em triplicata. A curva padrão foi ajustada pelo método dos mínimos quadrados e a adequação ao modelo linear empregado $(\mathrm{Y}=\mathrm{bx})$ foi a $5 \%$ de probabilidade [8].

\section{3 - RESULTADOS E DISCUSSÃO}

\section{1 - Definição da fase móvel e tempo de eluição}

Inicialmente, empregou-se as mesmas condições cromatográficas, descritas por ALPERT [2], ou seja, trabalhou-se em modo isocrático, utilizando uma fase móvel constituida de $10 \mathrm{mmoles} / \mathrm{L}$ de trietilaminofosfato (TEAP), pH 2,8 e 80\% de acetonitrila. Não sendo possivel conseguir uma boa separação dos oito aminoácidos essenciais e, ainda, obtendo-se um tempo de eluição muito longo, foram testadas, posteriormente, outras condições de análise. Assim, reduziu-se a concentração de TEAP de 10 mmoles/L para $5 \mathrm{mmoles} / \mathrm{L}$, e variou-se a proporção de acetonitrila entre 60 e $80 \%$. Testou-se, também, a alteração do fluxo de eluição em 0,5, 0,8 e 1,0mL/min e do $\mathrm{pH}$ da solução de TEAP em 1,6; 2,6 e 3,6. O comprimento de onda a $215 \mathrm{~nm}$ foi o único parâmetro que permaneceu inalterado.

Estes testes levaram à definição de uma fase móvel que permitiu a separação e identificação de todos os oito aminoácidos essenciais em um tempo total de eluição de 46min (Figura 1), inclusive a lisina, que não foi mencionada por ALPERT [2]. 


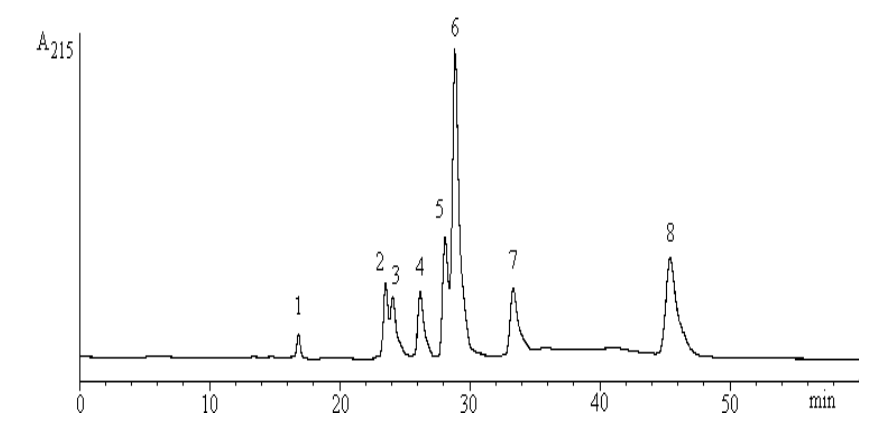

Condições empregadas: coluna PHEA, fase móvel 70\% ACN/30\% TEAP $5 \mathrm{~mm}$, fluxo $1 \mathrm{~mL} / \mathrm{min}, 215 \mathrm{~nm}$. Aminoácidos: (1) lisina; (2) triptofano; (3) fenilalanina; (4) leucina; (5) isoleucina; (6) metionina; (7) valina e (8) treonina.

FIGURA 1. Mistura padrão de aminoácidos essenciais separados através da HILIC.

Ao se comparar o tempo total de corrida cromatográfica dos aminoácidos essenciais, obtidos por dois métodos, observa-se na Tabela 1 que, pela HILIC foram necessários cerca de $45 \mathrm{~min}$, o que representa o dobro do tempo gasto na HPLC-RP (por volta de 23min). Entretanto, considerando-se, também, o tempo gasto no preparo da amostra, a técnica aqui proposta é mais rápida, pois não emprega a derivação que, em alguns casos, pode elevar a duração das análises em até 90min [3].

TABELA 1. Tempo de corrida cromatográfica da mistura de aminoácidos essencias analisados empregando-se diferentes métodos de HPLC.

\begin{tabular}{lccc}
\hline & \multicolumn{3}{c}{ Tempo de Corrida (minutos) } \\
\hline Aminoácidos & $\mathrm{A}$ & $\mathrm{B}$ & $\mathrm{C}$ \\
Lisina & 16.8 & 23.2 & 22.7 \\
Triptofano & 23.5 & 19.1 & - \\
Fenilalanina & 24.1 & 19.5 & 17.3 \\
Leucina & 26.2 & 18.6 & 16.3 \\
Isoleucina & 28.1 & 18.3 & 16.1 \\
Metionina & 28.8 & 17.8 & 15.2 \\
Valina & 33.3 & 16.9 & 14.6 \\
Treonina & 45.4 & 14.7 & 11.8 \\
\hline
\end{tabular}

Os dados são apresentados em minutos. A: HILIC, resultados do presente trabalho; B: HPLC-RP; VENDREL \& AVILES [21] e C: HPLC-RP; BADOUD \& PRATZ [3].

Nota-se, ainda que, como relatado por ZHU, MANT \& HODGES [24] e ALPERT [2], a ordem de eluição dos aminoácidos pela HILIC é a inversa da apresentada pela HPLC-RP.

\section{2 - Linearidade, limite de quantificação e precisão}

A correlação entre as quantidades utilizadas e as áreas dos picos obtidas revelaram, para todos os aminoácidos estudados, uma boa linearidade na faixa de 0,02nmol a 1100nmoles. Por outro lado, ao empregar a HPLC-RP, outros autores conseguiram esta linearidade trabalhando com quantidades menores de aminoácidos 200pmol-400pmol [9]; 1-800pmol [16]; 0,24 a 22,6ppm [17]. O limite de deteção da HILIC variou de 0,02nmol a 200nmoles, sendo superior a outros encontrados na literatura com o uso da HPLC-RP, após a derivação précoluna: 1,0-2,0ng [17], 0,5-1,0pmol [18]. Os valores destes autores, entretanto, relaciona-se a vários outros aminoácidos detectados, além dos essenciais. A repetibilidade do método de HILIC foi observada injetando-se, em triplicata, cinco concentrações diferentes de cada aminoácido padrão, obtendo-se, em 54\% e 30\% dos casos, um coeficiente de variação $(\mathrm{CV})$ inferior a $5 \%$ e $1 \%$, respectivamente. Apenas para a lisina, a repetibilidade do método não foi satisfatória, apresentando um CV entre $7 \%$ e $35,7 \%$.

Dentre os trabalhos encontrados na literatura, apenas CARISANO [6], testou a repetibilidade do método, no qual empregou-se a derivação pré-coluna com 4-cloro-7-nitrobenzenofurazona (NBD-Cl), seguida da separação por HPLC-RP, para a determinação dos aminoácidos presentes no suco de uva, obtendo um C.V de 3,08\%. Em outros artigos, determinou-se a reprodutibilidade das técnicas de determinação dos aminoácidos [10, 18, 19].

\section{3 - Análise dos hidrolisados de caseina}

Neste trabalho, analisou-se o teor dos aminoácidos essenciais, presentes nas frações cromatográficas dos hidrolisados H1, H2 e H3 (Tabela 2).

TABELA 2. Teor de aminoácidos essenciais presentes nas frações cromatográficas dos hidrolisado de caseína H1, H2 e H3.

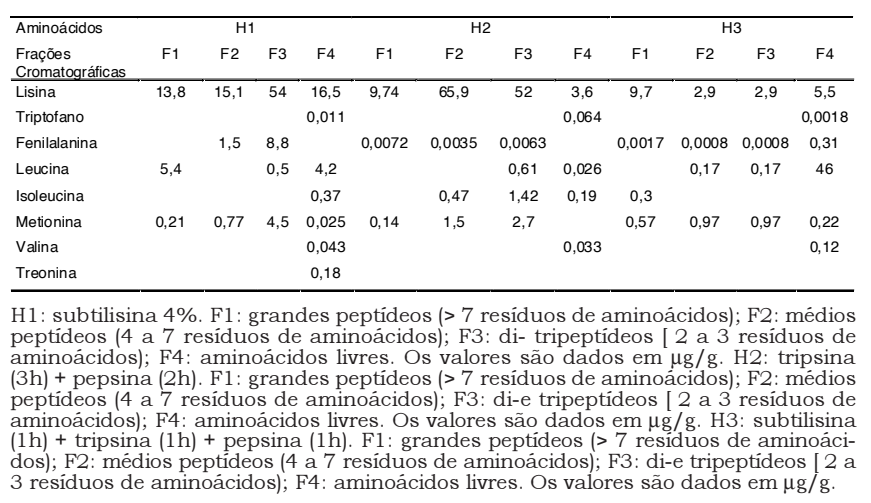

Pode-se observar que a lisina foi o único aminoácido presente em todas as frações cromatográficas estudadas. A metionina, não foi detectada apenas na fração F4 do hidrolisado H2, e por outro lado, a treonina foi identificada exclusivamente, na fração F4, do hidrolisado $\mathrm{H} 1$. Levando-se em conta que o triptofano é totalmente destruído na hidrólise ácida, a sua detecção somente foi possivel na fração F4. De acordo com trabalhos realizados anteriormente (dados do autor ainda não publicados [15]; o hidrolisado $\mathrm{H} 1$ apresentou niveis mais elevados de di- tripeptideos (F3) e os mais reduzidos de aminoácidos livres (F4), possuindo o melhor perfil para ser utilizado em dietas especiais. Somando-se a isso, a qualidade nutricional do $\mathrm{H} 1$ pode ser realçada, uma vez que, neste hidrolisado, observou-se o maior conteúdo de aminoácidos essenciais, na forma de di- tripeptídeos, dentre todos os casos estudados. 


\section{4 - CONCLUSÕES}

Após o ajuste de algumas condições analiticas, o emprego de cromatografia liquida de alta eficiência hidrofilica, através da coluna PHEA, revelou-se eficiente para a separação, identificação e quantificação dos aminoácidos essenciais. Esta técnica apresentou boa linearidade e precisão e, pela primeira vez, foi utilizada para a determinação dos aminoácidos das frações cromatográficas de hidrolisados protéicos (caseina), mostrando-se um meio útil para uma avaliação complementar do valor nutricional destas preparações.

\section{5 - REFERÊNCIAS BIBLIOGRÁFICAS}

[1] ALAIZ, M; NAVARRO, J.L; GIRON, J; VIOQUE, E. Amino acids analysis by high-performance liquid chromatography after derivatization with diethyl ethoxymethylenemalonate. Journal of Cromatography, Amsterdam, v. 591, n. 1, p. 181-186, 1992.

[2] ALPERT, A . J. Hydrophilic - interaction chromatography for the separation of peptides, nucleic acids and other polar compounds. Journal of Chromatography, v. 499, n. 2, p. 177-196, 1990.

[3] BADOUD, R; PRATZ, G. Simple and rapid quantitative determination of lysinoalanine and protein hydrolysate amino acids by high-performance liquid chromatography after derivatization with dansyl chloride. Chromatographia, Denver, v. 19, n. 6, p. 155-164, 1984.

[4] BEJOSANO, F.P; CORKE, H. Protein quality evaluation of Amaranthus whole meal flours and protein concentrates. Jounal of Science Food Agricultural, Great Britain, v. 76, n. 1, p. 100-106, 1998.

[5] BIDLINGMEYER, B. A ; COHEN, S. A ; TARVIN, T. L. Rapid analysis of amino acids using pre-column derivatization. Journal of Chromatography, Amsterdam, v. 336, n. 1, p. 93-104, 1984.

[6] CARREIRA, R.L.; MOTTA, S.; SILVESTRE, M.P.C. Otimização da hidrólise da caseína para elevar o teor de pequenos peptídeos: 2. Emprego da pepsina em associação com a tripsina e a subtilisina. Ciênc. Tecnol. Aliment., Campinas, 2001 (Aceito em Julho).

[7] CARISANO, A . Rapid and sensitive method for the determination of proline by reversed-phase high performance liquid chromatography with automated pre-column fluorescence derivatization. Journal of Chromatography, Amsterdam, v. 318, n. 1, 132-138, 1985.

[8] DRAPER, N; SMITH,H. Applied regression analysis. Second Edition. John Wiley \& Sons, INC, EUA, 1981, 709p.

[9] FESTE, A .S . Reversed-phase chromatography of phenylthiocarbamyl amino acid derivativos of physiological amino acids: na evaluation and a comparison with analysis by ion-exchange chromatography. Journal of Chromatography, Amsterdam, v. 574, n. 1, p. 23-34, 1992.

[10] HOOGERHEIDE, J.G; CAMPBELL, C.M. Determination of cysterine plus half-cystine in protein and peptide hydrolysates: use of dithiodioglycolic acid and phenylisothiocyanate derivatization. Analytical Biochemistry, San Diego, v. 201, n. 1, p. 146-151, 1992.

[11] KAN, T. A ; SHIPE, N. F. Modification an evaluation of a reversed phase high performance liquid chromatographic method for amino acid analysis. Journal of Food Science, Chicago, v. 46, p. 337-341, 1981.
[12] KIPP, B; BELITZ, H. D; SEILMEIER, W; WIESER, H. Comparative studies of high Mr. Subunits of rye and wheat. I. Isolation and biochemical characterisation and effects on gluten extensibility. Journal of Cereal Science, v. 23, n. 3, p. 227-234, 1996.

[13] LIU, H.J; CHANG, B.Y; YAN, H.W; YU, F.H; LIU, X.X. Determination of amino acids in food and feed by derivatization with 6-aminoquinolyl-Nhydroxysuccinimedyl carbomate and reversed phase liquid chromatographic separation. Journal of AOAC International, v. 78, n. 3, p. 736-744, 1995.

[14] MOORE, S; SPACKMAN, D.H; STEIN, N.H. Chromatography of amino acids on sulfonated polystyrene resins. Analytical Chemistry, v. 30, n. 7, p. 1185-1190, 1958.

[15] MORATO, A. F.; CARREIRA, R.L.; JUNQUEIRA, R.G.; SILVESTRE, M.P.C. Optimization of casein hydrolysis for obtaining high contentes of small peptides: use of subtilisin and trypsin. Journal of Food Composition and Analysis, Rome, v. 13, n. 3, p. 843 - 857, 2000.

[16] OSHODI, A . A .; IPINMOROTI, K.O; ADEYEYE, E.I; HALL, G.M. Amino and fatty acids composition of africam yam bean (Sphenostylis stenocarpa) flour. Food Chemistry, Great Britain, v. 53, n. 1, p. 1-6, 1995.

[17] PALMERO, S.; MARCHIS, M.; PRATI, M.; FUGASSA, E. HPLC analysis of free amino acids of total proteins in cultured cells: na application to the study of rat sertoli cell protein metabolism. Analytical Biochemistry, v. 202, p. 152158, 1992.

[18] PAPADOYANNIS, I; SAMANIDOU, V; THEODORIDIS, G. Quick ans dimple simultaneous determination for some amino acids by reversed-phase HPLC with UV determination. Journal of Liquid Chromatography, v. 14, n. 7, p. 1409-1416, 1991.

[19] SILVESTRE, M. P. C.; HAMON, M.; YVON, M. Analyses of protein hydrolysates. 1 . Use of poly (2-hydroxyethylaspartamide)-silica column in size-exclusion chromatography for the fracionation of casein hydrolysates. Journal Agricultural Food Chemistry, Washingtom, v. 42, n. 12, p. 2778-2782, 1994a.

[20] SILVESTRE, M. P. C.; HAMON, M.; YVON, M. Analyses of protein hydrolysates. 2. Characterization of casein hydrolysates by a rapid peptide quantification method Journal Agricultural Food Chemistry, Washingtom, v. 42, n. 12 , p. 2783-2789, 1994b.

[21] VENDRELL, J; AVÉLES, F. Complete amino acids analysis of proteins by dabsyl derivatization and reversed-phase liquid chromatography, Journal of Chromatography, Amsterdam, v. 358, n. 3, p. 401-413, 1986.

[22] YAMADA, H; MORIYA, H; TSUGITA, A . Development of na acid hydrolysis method with high recoveries of tryptophan and cysteine for microquantities of protein. Analytical Biochemistry, San Diego, v. 198, n. 1, p. 1-5, 1991.

[23] ZEZZA, F; KERNER,J; PASCALE, M.R; GIANNINI, R; MARTELLI, E. A . Rapid determination of amino acids by high-performance liquid chromatography; release of amino acids by perfused rat liver. Journal of Chromatography, Amsterdam, v. 593, p. 99-101, 1992.

[24] ZHU, B. Y.; MANT, C. T.; HODGES, R. S. Hydrophilic interaction chromatography of peptides on hydrophilic and strong cation-exchange columns. Journal of Chromatography, Amsterdam, v. 558, n. 1, p. 13-24, 1991.

\section{6 - AGRADECIMENTOS}

Os autores agradecem ao CNPq e à FAPEMIG pelo apoio financeiro. 